\title{
Apresentação - Desigualdades, vulnerabilidades e reconhecimento: em busca de algumas invisibilidades produzidas nas políticas de saúde
}

\author{
Marcelo Eduardo Pfeiffer Castellanos \\ Sociólogo, professor associado do Instituto de Saúde Coletiva \\ da Universidade Federal da Bahia (ISC/UFBA). \\ E-mail: mcastellanosळufba.br

\section{Tatiana Wargas de Faria Baptista} \\ Psicóloga, pesquisadora do Departamento de Administração e \\ Planejamento em Saúde da Escola Nacional de Saúde Pública \\ Sergio Arouca da Fundação Oswaldo Cruz (ENSP/Fiocruz). \\ E-mail: twargasळensp.fiocruz.br
}

As desigualdades sociais extremas aumentam no Brasil e no mundo. As diversas crises do capitalismo parecem atuar muito mais como um motor da reinvenção do capital do que das suas formas de superação. Alguns dizem que o capitalismo vive das crises (ou das suas respostas a estas). Isto porque as crises têm impulsionado (e são apresentadas como justificativa para) novas formas de exploração. A atual reinvenção do capital, por exemplo, caminha em direção à sua financeirização, à fragilização dos Estados Nacionais, à precarização do trabalho, dentre outras ações, sustentadas em discursos e políticas que afirmam a austeridade e o Estado Mínimo como via única para evitar o colapso do sistema produtivo e do próprio Estado. Vivemos atualmente, no Brasil e no mundo, capítulos dramáticos dessa conjuntura, em que novas e antigas formas de fragilização dos direitos sociais avançam no âmbito de uma forte e clara estratégia de esfacelamento do sistema de proteção social. Uma estratégia que não só procura limitar os direitos sociais, mas também estereotipar e diminuir a capacidade de luta daqueles que os defendem. Essa situação afeta dramaticamente aqueles que são mais prejudicados com a limitação e/ou anulação de tais direitos, uma vez que se veem inseridos em contextos mais e mais intensos de vulnerabilidade, ao mesmo tempo que limitados em sua capacidade de reação e resistência.

A partir da "crise da sociedade assalariada" e da consequente desestabilização da integração social pelo trabalho, as "desigualdades multiplicadas" (Dubet, 2001) ganharam o primeiro plano das mobilizações sociais. Ou seja, antigas e novas formas de dominação passam a ser denunciadas, evidenciadas e tomadas como forte elemento organizador de experiências e identidades sociais. Trata-se de uma situação um tanto quanto paradoxal. Isto porque a defesa do Estado de BemEstar Social, historicamente dinamizada pelas 
lutas dos movimentos operários, perdeu força com a própria crise da sociedade assalariada. Ao mesmo tempo, é exatamente nesse contexto que outras "gramáticas ideológicas" passam a ser utilizadas para delinear os conflitos sociais e também defender os direitos sociais (base do Estado de Bem-Estar Social). Essas "gramáticas" apoiam-se em experiências e teorias sociais que não giram em torno do conflito capital/trabalho. Os movimentos feminista e negro são emblemáticos. As lutas indígenas, na América Latina, também têm inspirado reformulações das bases epistêmicas para se definir as situações e conflitos em jogo. As questões políticas, econômicas e identitárias relacionadas aos processos migratórios internacionais mostram também seus complexos arranjos e relações com o cenário aqui esboçado. Ocorre que isso tudo vem se dando exatamente em um contexto de esvaziamento do Estado de Bem-Estar Social ou marcado pela sua afirmação retórica, já que esvaziada de sustentação financeira e política.

Ao mesmo tempo, nessa conjuntura geral se fortalecem lutas pelo reconhecimento de identidades, culturas, bases epistêmicas e simbólicas diversas daquelas parametrizadas pelo conflito capital/trabalho, pelo homem branco e europeu etc. Portanto, a intensificação (e reinvenção) de antigas formas de exploração anda pari passu com novas formas de dominação e frentes de conflito. Diante dessas (nem tão) novas desigualdades sociais, surgem lentes teóricas sensíveis às relações sociais, processos históricos e conflitos específicos que estão em sua origem. Os estudos culturais, as teorias feministas, as várias vertentes da teoria do reconhecimento, os estudos pós-coloniais e decoloniais, as chamadas "epistemologias do sul" e os estudos interseccionais, para listar somente algumas dessas correntes teóricas, vêm fornecendo importantes contribuições para o deslocamento do olhar em direção a outras formas de dominação não redutíveis ao conflito capital/trabalho, por vezes ignorando-o por completo, por vezes incluindo-o em suas análises.

Porém e consequentemente, um dos grandes desafios presentes na análise das desigualdades sociais consiste em não somente recorrer a teorias sensíveis aos diferentes tipos de conflitos geradores de diversas ordens de desigualdade social; mas, também, o de inserir as análises realizadas em um quadro interpretativo mais amplo, em que essas teorias sejam acionadas de modo articulado (sem subordinar uma teoria a outra), de forma a considerar os múltiplos tipos e níveis de determinação dessas desigualdades, responsáveis por produzir "totalidades desvantajosas". Esse enquadramento mais amplo é relevante e necessário não apenas do ponto de vista científico, mas sobretudo político e social. Ou seja, para avançar no enfrentamento do conjunto das desigualdades sociais, de modo sensível às suas especificidades, precisamos manter um olhar amplo em que as relações entre cultura, poder e diferença não sejam segmentadas em análises que mantenham apartadas as dimensões econômicas, culturais e políticas como se desigualdades de classe respondessem unicamente a relações materiais e desigualdades étnicas se reduzissem à esfera simbólica. Nem um nem outro! Por isso mesmo, não podemos fazer de todas as diferenças (políticas, teóricas, metodológicas...) barreiras instransponíveis que apartam nossos corpos, corações e mentes, dando solidez à ideia do "cada um no seu quadrado". Devemos considerar, isto sim e com o devido peso, que as diferentes formas de dominação se beneficiam da desarticulação e esfacelamento dos movimentos, energias e identidades daqueles que lhes oferecem resistência. Nesse sentido, fica cada vez mais fortalecida a ideia (e desafio político e epistêmico) de que:

Temos o direito de ser iguais quando a nossa diferença nos inferioriza; e temos o direito de ser diferentes quando a nossa igualdade nos descaracteriza. Daía necessidade de uma igualdade que reconheça as diferenças e de uma diferença que não produza, alimente ou reproduza as desigualdades. (Santos, 2003, p. 53)

Este número temático foi pensado a partir da preocupação com a atual conjuntura política brasileira e mundial, mas também como uma tentativa, certamente não isolada, de indicar formas de superação de dicotomias e fragmentações que, muitas vezes, marcam o debate político e científico. Acreditamos que 
sem o aprofundamento desse debate será difícil engajar corpos, mentes e corações no melhor enfrentamento dos desafios que se apresentam, bem como produzir novos "acontecimentos" nos encontros entre ação e estrutura (especialmente se estamos interessados na produção de acontecimentos menos “desiguais”).

Muitos são os temas-chave para esse debate, bem mais numerosos e amplos do que aqueles que nos foi possível incluir neste número. Privilegiamos trabalhos de autores de diferentes regiões do país e em processo de consolidação no campo da saúde coletiva. Agradecemos aos autores que aceitaram o desafio de enviar suas contribuições, mesmo com tempos editoriais tão reduzidos como os que vigoraram na organização desta pequena coletânea.

Pequena, mas (esperamos) não menor! Afinal, dedicar o primeiro número do ano de 2018 ao tema das desigualdades sociais é algo, por si só, já significativo na linha editorial da revista. Procuramos priorizar trabalhos fundamentados em teorias sociais consistentes e bem orientadas para a compreensão de diferentes experiências e dimensões das desigualdades sociais, com adequada apresentação de material empírico e de análises de interesse; sendo essa também uma diretriz editorial.

Compõem o número temático três trabalhos que procuraram avançar na análise de algumas das atuais formas de produção e reprodução das desigualdades sociais presentes no contexto das políticas de saúde e/ou de suas interfaces com o cotidiano daqueles por elas focalizados. São apresentadas interessantes reflexões sobre os processos de vulnerabilização social e de invisibilização das experiências sociais dos grupos “dominados”, defendendo-se evitarmos a sua "vitimização", ao trazer à tona contradições e formas de resistência. Também, inclui-se uma entrevista com José Ricardo Ayres, em que se discute, por exemplo, a relevância desse conceito para a análise de algumas das questões anteriormente levantadas neste texto.

Sara Mota e Mônica Nunes iniciam seu texto lembrando que:

as lutas de grupos minoritários por reconhecimento social e pelo estabelecimento de uma ação estatal que combata a discriminação, favoreça a igualdade e permita a convivência entre populações de origens culturais e étnicas diferentes fazem parte da paisagem político-cultural do mundo contemporâneo. (p. 12)

Com esse argumento, as autoras se propõem a analisar os significados do princípio da "atenção diferenciada" nas práticas de gestores do Subsistema de Atenção à Saúde dos Povos Indígenas (Sasi) na Bahia e discutem a necessidade de permeabilizar os espaços de gestão de políticas públicas para a produção de efetivos encontros interculturais, de novos conceitos e sínteses. Há um longo caminho a percorrer, no Brasil, no enfrentamento das desigualdades produzidas e mantidas por relações coloniais de poder no que tange aos direitos dos povos indígenas, mas há também um caminho em curso que merece ser aprofundado. Procurando realizar uma apropriação crítica e reflexiva do conceito de multiculturalismo - e apoiando-se para tanto em algumas formulações de Boaventura de Souza Santos - as autoras mostram como a afirmação das diferenças culturais assume vários sentidos nos relatos produzidos pelos gestores do Sasi-BA. Muitas vezes, paradoxalmente, essa afirmação serve ao discurso de negação e esvaziamento da chamada “atenção diferenciada”, seja por assumir um tom meramente retórico e sem consequência prática, seja por ser identificada como barreira ou elemento dificultador da gestão desse sistema, ao demarcar distâncias entre os interesses e perspectivas indígenas e a lógica institucional-burocrática e sanitária que orienta as práticas dos gestores. A negação de diferenças culturais (especialmente, no plano das práticas de cura), também, foi identificada como justificativa assumida por alguns gestores para a não oferta de uma atenção diferenciada. Enfim, nessa miríade de posições, concretiza-se a não atenção às necessidades em saúde específicas da população indígena na Bahia, quer seja através do avanço de sua medicalização social, quer seja pelas barreiras de acesso ao Sasi-BA. Esta última situação torna-se tanto mais grave e comum quanto levamos em consideração que, na Bahia, a maior parte dessa população é não aldeada, e, portanto, vive longe dos serviços específicos a ela destinados. 
Denise Martin, Alejandro Goldberg e Cássio Silveira trazem para a cena os recentes processos migratórios internacionais ocorridos no Brasil com o objetivo de refletir sobre os processos de inclusão de imigrantes e refugiados nas instituições de saúde. A partir da lente das ciências sociais e humanas discutem os desafios que se apresentam no reconhecimento e inclusão dessas pessoas nos sistemas oficiais de saúde e como, muitas vezes, são submetidos a regras, tradições e valores do sistema receptor, que dificultam a formação de um espaço de convivência que garanta o respeito às diferenças e à diversidade. Os autores alertam que tanto os serviços de saúde como a área acadêmica precisam ampliar e aprofundar a reflexão sobre como lidamos com esse "outro", o "imigrante" ou o "refugiado", indicando a importância da questão na contemporaneidade. Ampliar, no sentido de considerar a pobreza, indigência e desigualdade como elementos presentes nas experiências dos imigrantes e refugiados - experiências, portanto, não "redutíveis" ao âmbito cultural. Aprofundar, no sentido de evitar rótulos e estereótipos (como o da "vitimização"), produzidos por olhares e ações redutores da experiência e perspectiva desses sujeitos.

Contextos de vulnerabilização e práticas de saúde é o tema tratado no texto de Roberta Gondim de Oliveira que, a partir do acompanhamento de profissionais de saúde no atendimento prestado a pessoas em situação de rua (PSR), discute a vulnerabilização de vidas humanas e problematiza a relação entre políticas públicas, vulnerabilidade, sofrimento humano e negligência de pessoas e territórios. A autora faz uma aposta na potência do diálogo crítico e nos "encontros situados" de saúde, na construção de cotidianos possíveis para sujeitos historicamente postos à margem de uma dada sociedade. Em seu texto, a autora lembra que a população em situação de rua reconfigura-se enquanto questão social, tanto a partir da expansão dos grandes centros urbanos, em que a multiplicidade de agenciamentos tece conexões e fluxos discursivos - institucionais, políticos, midiáticos, reivindicatórios, coercitivos, quanto a partir da mobilização política das próprias PSR. Os movimentos sociais das PSR impulsionam a superação de narrativas culpabilizantes, individualizantes e benevolentes, muitas vezes, presentes naqueles agenciamentos. A autora também problematiza a noção de inclusão/exclusão centralmente presente em políticas públicas de saúde e em políticas especificamente voltadas às PSR, ao apontar o caráter colonizador dessa noção (e das políticas!), quando partem de concepções universalizantes de família, bem-estar, corpo etc., negando outras possibilidades de existência. Ao mesmo tempo, ela chama atenção para a importância da recente formulação de políticas e dispositivos assistenciais especificamente voltados à PSR. Para ela, essas políticas e dispositivos se mostram mais dialógicos e próximos aos movimentos sociais das PSR e de suas realidades. Porém, ainda que signifique um avanço, a autora chama atenção para outro perigo - o de haver uma "inclusãosegmentação", operada por políticas e dispositivos muito específicos, exclusivamente voltados a esse segmento populacional, que acabem por substanciar vulnerabilidades e a ideia de que se tratam de sujeitos que devem ser vistos “à parte" de outros usuários dos serviços de saúde, por exemplo. Nada está escrito na pedra, afinal, como afirma Roberta Gondim de Oliveira:

os contornos, caminhos e sentidos assumidos pela política dependem da complexidade dos agenciamentos - técnicos, políticos e sociais, e da amplitude das conexões, em que um conjunto de elementos e atores desempenha papel de destaque na luta política, principalmente o dos movimentos sociais. (p. 46)

A entrevista com José Ricardo Ayres compõe o debate sobre vulnerabilidade com elementos sobre a história do conceito, vantagens e perigos no seu uso. Discutem-se os efeitos da utilização do conceito atrelado a determinados grupos populacionais, então denominados "vulneráveis" (crianças, idosos, drogaditos, população em situação de rua etc.), e como tal adjetivação pode levar à naturalização de situações iminentemente sociais. Ayres retoma aspectos de sua trajetória e nos conta como se aproximou de outros aportes 
teóricos, como a teoria do reconhecimento, de Axel Honneth, para reforçar a análise das relações entre intersubjetividade e contextos sociais. Ele entende que esse é um bom caminho para fortalecer a análise das relações e processos de vulnerabilização e para evitar a naturalização do conceito eventualmente operada em estudos sobre "populações vulneráveis". Reforçar as relações e os processos de vulnerabilização significa garantir o espaço para a escuta, o reconhecimento do sofrimento e a explicitação das relações que produzem o adoecimento. Nas palavras de Ayres:

a gente sabe que existem pessoas que estão em situações mais desfavoráveis (e elas têm que ser consideradas especialmente), mas devemos considerar que a partir do sofrimento delas, a partir do desrespeito a que estão submetidas, a gente deve identificar o que não está sendo reconhecido ali, o que está provocando aquela situação e que precisa ser transformado nas nossas relações. Em geral, quando a gente faz isso, quem se beneficia não são só aquelas pessoas que estão sofrendo mais, é todo mundo, é a nossa humanidade que se enriquece. (p. 59)

Trata-se, portanto, de uma aposta potente para o campo da saúde coletiva, porque possibilita aproximar análises que consideram as relações entre estrutura social, (inter)subjetividade e ação social. Para o autor, trata-se de uma perspectiva acadêmica, mas também política e implicada com a vida, porque possibilita "pensar no grau de compartilhamento de certas vulnerabilidades, no modo como ela se constitui e distribui nas relações sociais que estamos sempre construindo, para que a gente possa ajudar a melhorar a vida de todo mundo" (p. 6o).

O conjunto dos três artigos e da entrevista apontam para a importância de se abordar o tema das desigualdades sociais a partir de enfoques integradores que procurem não segmentar demais as análises, nem substancializar as vulnerabilidades ou reduzir as desigualdades ao acesso a bens e serviços (incluídos os recursos e serviços de saúde) ou a reflexos das posições assumidas nas estruturas sociais. As desigualdades sociais em saúde são produzidas em diversos contextos e relações sociais em que se delineiam processos de vulnerabilização e de resistência à colonização das identidades, das sensibilidades, do agir e da vida! É interessante notar que os estudos aqui incluídos mostram que, dentre os contextos de vulnerabilização, encontram-se aqueles produzidos pelas próprias políticas de saúde dirigidas às populações indígenas, às populações em situação de rua e aos refugiados/imigrantes. Esses contextos de vulnerabilização, no entanto, são sensíveis às mobilizações sociais em busca do reconhecimento e da superação das invisibilidades e ausências produzidas. Isso se dá, muitas vezes, a partir de ações e posicionamentos contraditórios, não redutíveis a estereótipos simplificadores.

Com a publicação destes estudos, gostaríamos de defender a importância de pensar a análise das políticas de saúde a partir das relações entre cultura, poder e diferença. Acreditamos que esse tipo de análise - dentre outras que não oponham a dimensão material à dimensão simbólica, ou que evitem segmentar a esfera política de outras esferas da vida social - podem beneficiar bastante a ampliação da compreensão das disputas e lutas sociais que atravessam diferentes instâncias das políticas de saúde e que, por vezes, não são devidamente consideradas nos enfoques hegemonicamente presentes na produção científica. Nesse sentido, essa publicação representa mais um passo na direção de superar uma outra "invisibilidade" aquela produzida em relação à análise de políticas de saúde realizada por estudos "antropológicos" ou "sociológicos" ou, dito de outro modo, às contribuições destes estudos para a análise das políticas de saúde. Pensar as diferenças de enfoques e contribuições mútuas entre tais estudos e aqueles produzidos ao interior do que se convencionou chamar da área de "política, planejamento e gestão", acreditamos, representa um passo importante para a reinvenção de fronteiras menos rígidas (“cada um no seu quadrado") e a encontros menos desiguais na própria saúde coletiva.

Encerramos com um convite à leitura destes textos na expectativa de provocar novos debates e reflexões, como bilhetes inseridos em garrafas que são jogadas ao mar; bilhetes estes que quando encontrados transmitem recados e provocam 
reações diferentes, inusitadas, potentes e novas. Os textos aqui produzidos já produziram em nós alguns deslocamentos que afetam nosso caminhar. Seguiremos novas jornadas, marcados pelas leituras sobre as desigualdades e os processos de vulnerabilização, pelas dificuldades de reconhecimento do "Outro" em sua diversidade e diferença, pelas análises das invisibilidades produzidas, pela necessidade do olhar atento ao que se produz "de vida" no cotidiano. Não somente afetado pelas políticas, mas também invasor e transgressor destas. Trata-se de um começo, dentre muitos possíveis, que requisita outros passos que, acreditamos, virão!

\section{Referências}

DUBET, F. As desigualdades

multiplicadas. Revista Brasileira de Educação, Rio de Janeiro, n. 17, p. 5-18, 2001. Disponível em:

<http://bit.ly/2Fkxhzl>. Acesso em: 5 mar. 2018.

SANTOS, B. S. Reconhecer para libertar: os

caminhos do cosmopolitanismo multicultural. Rio de Janeiro: Civilização Brasileira, 2003. 